Тихомирова Наталья Александровна, д.т.н., профессор, Зверев Дмитрий Сергеевич, к.б.н., доцент

ГОУ ВО Московской области Государственный социально-гуманитарный университет, г. Коломна

\title{
ЭКСПЕРТИЗА КАЧЕСТВА КИСЛОМОЛОЧНЫХ НАПИТКОВ
}

Аннотация. В работе представлена экспертиза качества кисломолочных напитков фермерского и промышленного производства, реализуемых в розничной сети юго-востока Московской области, на примере ряженки.

Ключевые слова: ряженка, экспертиза качества кисломолочных напитков.

\section{Tikhomirova Natalya Alexandrovna, Doctor of Technical Science, Professor, Zverev Dmitriy Sergeevich, Candidate of Biological Science, Docent \\ State Social and Humanitarian University, Kolomna, Russia}

\section{QUALITY EXAMINATION OF SOUR-MILK DRINKS}

Annotation. The paper presents quality examination of sour-milk drinks of farm and industrial production, sold in retail network of south-east of Moscow region, on example of ryazhenka (fermented baked milk).

Key words: ryazhenka, quality examination of sour-milk drinks.

Ассортимент жидких кисломолочных продуктов разнообразен и с каждым годом их число увеличивается. По органолептическим показателям их условно разделяют на питьевые и пастообразные. Условно жидкие кисломолочные продукты классифицируют по способу производства, по виду брожения и используемых микроорганизмов. По способу производства жидкие кисломолочные продукты вырабатывают термостатным и резервуарным способами. В соответствие с действующими нормативными документами [1] жидкие кисломолочные продукты могут выпускаться с термической обработкой после сквашивания и без неё, с различной массовой долей жира (табл. 1), а в зависимости от используемого молочного сырья из натурального, нормализованного, восстановленного, рекомбинированного молока или их смесей.

На современном прилавке розничной сети РФ ассортимент кисломолочных напитков с учетом различных видов молочного сырья, заквасочных культур, жирности, наполнителей, видов упаковки составляет более тысячи наименований. При этом их можно систематизировать по видовым группам: кефир; кумыс; ацидофильные продукты; национальные виды простокваши, включая йогурт, ряженку, варенец, катык, мацони, мацун, сузьму и др. Анализ структуры ассорти- 
мента кисломолочных напитков в РФ по данным Росстата показывает, что лидирующее место занимают три напитка, а именно: кефир (около 60,0\%); йогурт (около 25,0\%) и ряженка (более 12,0 \%). Ряженка относится к группе простокваш, на долю которых приходится всего около 3,0\% ассортимента кисломолочных напитков в розничной сети. Учитывая широту ассортимента простокваши и высокие потребительские свойства ряженки, которая входит в ее группу, была проведена оценка потребительских предпочтений методом анкетирования и анализа ассортимента в розничной сети юго-востока Московской области [2].

Таблица 1 - Ассортимент кисломолочных напитков

\begin{tabular}{|l|c|c|c|c|c|c|c|}
\hline $\begin{array}{l}\text { Жидкие кисломолоч- } \\
\text { ные продукты, жирно- } \\
\text { стью, \% }\end{array}$ & $\begin{array}{c}\text { Обез- } \\
\text { жирен- } \\
\text { ный }\end{array}$ & $\begin{array}{c}\text { Не- } \\
\text { жир } \\
\text { ный }\end{array}$ & $\begin{array}{c}\text { Мало- } \\
\text { жирный }\end{array}$ & $\begin{array}{c}\text { Класс- } \\
\text { сиче- } \\
\text { ский }\end{array}$ & $\begin{array}{c}\text { Норма } \\
\text { льной }\end{array}$ & $\begin{array}{c}\text { Жир- } \\
\text { ный }\end{array}$ & $\begin{array}{c}\text { Высо- } \\
\text { кожир- } \\
\text { ный }\end{array}$ \\
\hline $\begin{array}{l}\text { Не подвергнутые тер- } \\
\text { мической обработке } \\
\text { после сквашивания }\end{array}$ & $\begin{array}{c}\text { Не бо- } \\
\text { лее } 0,1\end{array}$ & $\begin{array}{c}\text { От } 0,3 \\
\text { до } 1,0\end{array}$ & $\begin{array}{c}\text { От } 1,2 \\
\text { до } 2,5\end{array}$ & $\begin{array}{c}\text { От } 2,7 \\
\text { до } 4,5\end{array}$ & - & $\begin{array}{c}\text { От 4,7 } \\
\text { до 7,0 }\end{array}$ & $\begin{array}{c}\text { От 7,2 } \\
\text { до 9,5 }\end{array}$ \\
\hline $\begin{array}{l}\text { Подвергнутые терми- } \\
\text { ческой обработке по- } \\
\text { сле сквашивания }\end{array}$ & $\begin{array}{l}\text { Не бо- } \\
\text { лее } 0,1\end{array}$ & $\begin{array}{l}\text { От } 0,3 \\
\text { до } 1,0\end{array}$ & $\begin{array}{l}\text { От } 1,2 \\
\text { до } 2,5\end{array}$ & - & $\begin{array}{l}\text { От } 2,7 \\
\text { до 4,5 }\end{array}$ & $\begin{array}{l}\text { От 4,7 } \\
\text { до 7,0 }\end{array}$ & $\begin{array}{c}\text { От 7,2 } \\
\text { до 9,5 }\end{array}$ \\
\hline
\end{tabular}

В результате проведенной работы для товароведной экспертизы были отобраны по три образца ряженки промышленного и фермерского производства с массовой долей жира 4,0 процента. Информационная идентификация экспериментальных образцов представлена в табл.2.

Таблица 2 - Информационная идентификация экспериментальных образцов ряженки

\begin{tabular}{|l|c|c|c|c|}
\hline \multicolumn{1}{|c|}{ Показатель по требованиям ТР ТС } & \multicolumn{3}{|c|}{ Наименование образца } \\
\cline { 2 - 5 } & $\begin{array}{c}\text { Фермер- } \\
\text { ский об- } \\
\text { разец }\end{array}$ & $\begin{array}{c}\text { «Кремлев- } \\
\text { ское каче- } \\
\text { ство» }\end{array}$ & $\begin{array}{c}\text { «Молоч- } \\
\text { ное цар- } \\
\text { ство» }\end{array}$ & $\begin{array}{c}\text { «Русское } \\
\text { молоко» }\end{array}$ \\
\hline наименование пищевой продукции & - & + & + & + \\
\hline состав пищевой продукции & - & + & + & + \\
\hline количество пищевой продукции & - & + & + & + \\
\hline дата изготовления пищевой продукции & - & + & + & + \\
\hline срок годности пищевой продукции & - & + & + & + \\
\hline условия хранения пищевой продукции & - & + & + & + \\
\hline $\begin{array}{l}\text { наименование и место нахождения изгото- } \\
\text { вителя пищевой продукции }\end{array}$ & - & + & + & + \\
\hline $\begin{array}{l}\text { рекомендации и (или) ограничения по ис- } \\
\text { пользованию }\end{array}$ & - & + & + & + \\
\hline $\begin{array}{l}\text { показатели пищевой ценности пищевой } \\
\text { продукции }\end{array}$ & - & + & + & + \\
\hline $\begin{array}{l}\text { сведения о наличии в пищевой продукции } \\
\text { компонентов, полученных с применением } \\
\text { ГМО }\end{array}$ & - & + & + & + \\
\hline $\begin{array}{l}\text { единый знак обращения продукции на } \\
\text { рынке государств - членов Таможенного } \\
\text { союза. }\end{array}$ & - & + & + & + \\
\hline
\end{tabular}


У отобранных образцов проверяли целостность упаковки, проводили количественную идентификацию, определяя массу нетто и брутто. Образцы ряженки фермерского производства были расфасованы весом около 500г и упакованы в пластиковые коробочки с негерметичной крышкой без этикетки и какойлибо информации о товаре. Комплект необходимой информации на партию товара, включая ветеринарно-санитарное заключение, у продавцов был в наличии. Промышленные образцы ряженки были упакованы в традиционные виды упаковки по 500г: ряженка «Кремлевское качество» - в пет-бутылку; «Молочное царство» и «Русское молоко» - в многослойный пакет типа пюр-пак. На всех упаковках отобранных образцов ряженки промышленного производства была представлена информация в соответствии с ТР ТС 05 и ТР ТС 021, информационные и манипуляционные знаки. Была проведена оценка так называемого правила «3Д» о товаре: достоверность, достаточность и доступность. Анализ штрих-кодов на промышленных образцах ряженки подтвердил легальность их производства и соответствие заявленной информации на этикетках.

Для органолептической и физико-химической экспертизы провели отбор точечных проб и сформировали объединенную пробу в соответствии с ГОСТ 26809.1-2014 «Правила приемки, методы отбора и подготовка проб к анализу». Оценку проводили в соответствии с действующей НТД.

В соответствии с ТР ТС 033 ряженка - это кисломолочный продукт, произведенный путем сквашивания топленого молока с добавлением молочных продуктов или без их добавления с использованием заквасочных микроорганизмов - термофильных молочнокислых стрептококков с добавлением болгарской молочнокислой палочки или без ее добавления, который на конец срока годности должен содержать не менее 10 миллионов молочнокислых микроорганизмов в мл ( не менее $\left.1 \times 10^{7}\right)$.

Производство ряженки - это сложный биохимический процесс, в результате которого образуется свойственный только данному кисломолочному напитку вкус и запах, консистенция и внешний вид. В процессе сквашивания происходят изменения практически всех компонентов молока. В первую очередь подвергается молочнокислому брожению лактоза. В результате расщепления лактозы образуется сначала глюкоза и галактоза, а в конечном счете молочная кислота, летучие органические кислоты, эфиры и пр. Для производства ряженки используют пастеризованное молоко при $95-98^{\circ} \mathrm{C}$ с выдержкой 3-5 ч, которое называют топленым. Заквашивание и сквашивание проводят при температуре 40-42 ${ }^{\circ} \mathrm{C}$ до образования сгустка. Кислотность готовой ряженки должна составлять от 80 до $120^{\circ} \mathrm{T}$. В зависимости от способа производства топленое заквашенное молоко при термостатном производстве сразу разливают в потребительскую упаковку и направляют в термостатную камеру для сквашивания. По окончании сквашивая упакованные образцы ряженки перемещают в холодильную камеру и по достижении температуры $6 \pm 2{ }^{\circ} \mathrm{C}$ направляют в экспедицию и торговлю. При резервуарном способе производства ряженки заквашивание, сквашивание и охлаждение готового продукта проходят в резервуаре с мешалкой и рубашкой, а на расфасовку и упаковку подается готовая охлажденная до $6 \pm 2{ }^{\circ} \mathrm{C}$ ряженка. Ап- 
паратурно-технологическая схема производства ряженки резервуарным способом с точками техно-химического и микробиологического контроля сырья, полуфабрикатов и готовой продукции представлена на рисунке 1 [3].
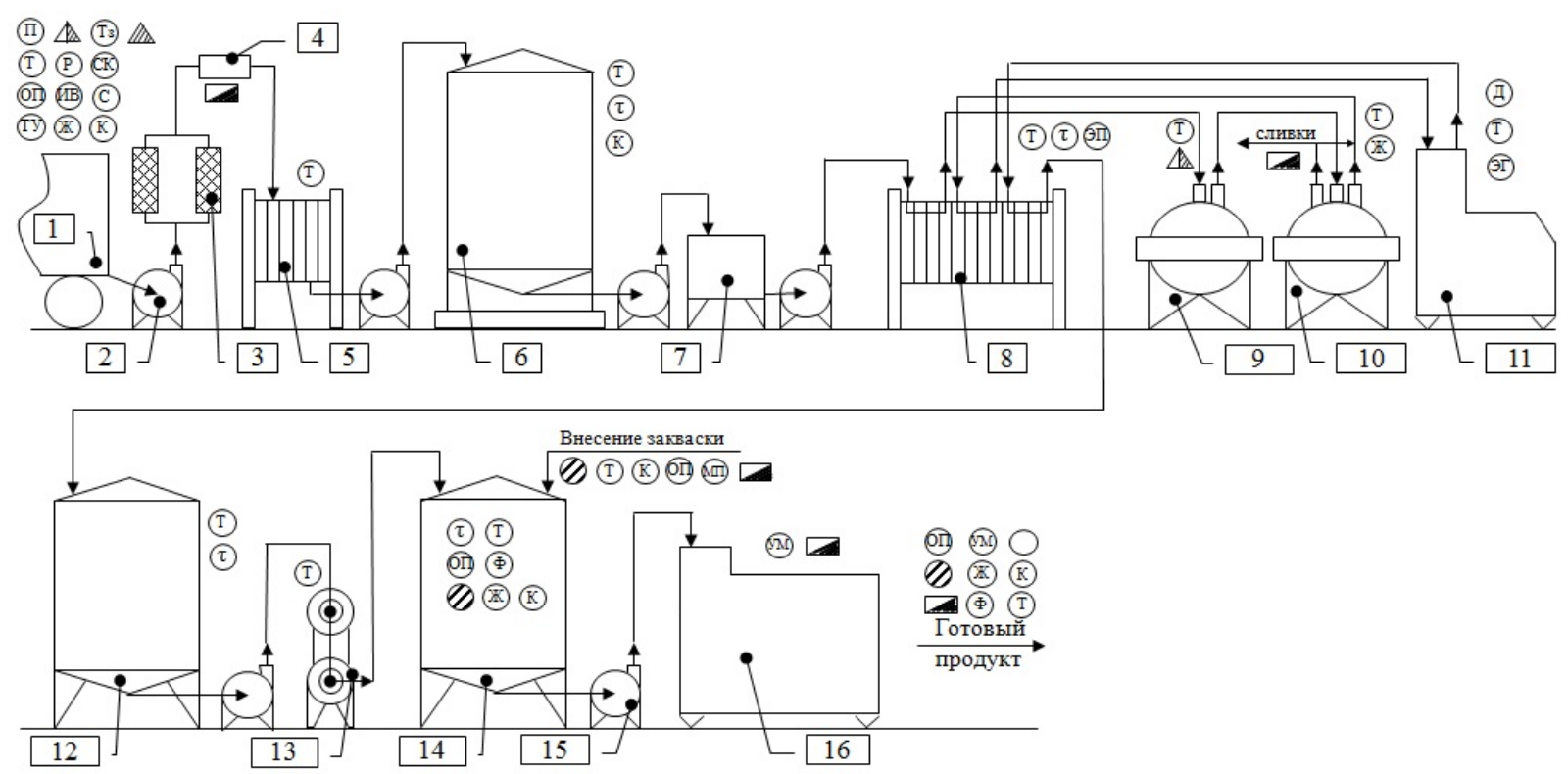

Рисунок 1 - Аппаратурно-технологическая схема производства ряженки с точками производственного контроля

Потребительские свойства, а именно консистенция, наличие пенки или отстоя жира, выделившаяся сыворотка, зависят от способа производства. Промышленные образцы отобранной ряженки соответствовали по потребительским свойствам ряженке резервуарного способа производства. Потребительские свойства ряженки фермерского производства, в том числе наличие неровного кусочка румяной корочки в каждой упаковке, свидетельствуют о термостатном способе производства большого объема кисломолочного продукта с последующей расфасовкой и упаковкой его в пластиковые коробочки с негерметичной крышкой. Оценку органолептических показателей проводили дегустационной комиссий. Оценку проводили по 5-ти балльной шкале. При оценке цвета все экспериментальные образцы ряженки получили по 5 баллов. По показателям «Вкус и запах», «Консистенция и внешний вид» фермерский образец и «Кремлевское качество» получили по 5 баллов, «Молочное царство» - 2 балла, а «Русское молоко» занимал промежуточное положение.

Оценка физико-химических показателей включала массовую долю жира и влаги, титруемую кислотность и влагоудерживающую способность свежих образцов и в процессе хранения. Результаты представлены в табл.4.

Анализ полученных данных свидетельствует о том, что массовая доля жира и влаги соответствовала нормативным показателям у образцов ряженки с товарными знаками: «Кремлевское качество» и «Русское молоко». Ряженка «Молочное царство» имела жирность - 2,8\%. Ряженка фермерских образцов имела

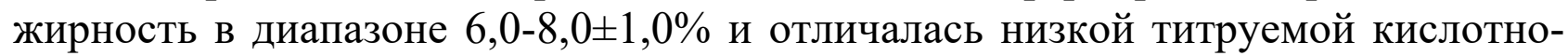


стью, при этом, имела, как и ряженка «Молочное царство», более низкую влагоудерживающую способность в сравнении с двумя другими промышленными образцами.

Таблица 3 - Результаты органолептической идентификации экспериментальных образцов ряженки

\begin{tabular}{|c|c|c|c|c|}
\hline \multirow{2}{*}{$\begin{array}{c}\text { Наимено- } \\
\text { вание по- } \\
\text { казателя }\end{array}$} & \multicolumn{4}{|c|}{ Экспериментальные образцы } \\
\hline & $\begin{array}{c}\text { Фермерский обра- } \\
\text { зец }\end{array}$ & $\begin{array}{c}\text { «Кремлевское ка- } \\
\text { чество» }\end{array}$ & $\begin{array}{c}\text { «Молочное цар- } \\
\text { ство» }\end{array}$ & «Русское мо \\
\hline $\begin{array}{l}\text { Конси- } \\
\text { стенция и } \\
\text { внешний } \\
\text { вид }\end{array}$ & $\begin{array}{c}\text { Однородная, с } \\
\text { нарушенным или } \\
\text { ненарушенным } \\
\text { сгустком без газо- } \\
\text { образования жид- } \\
\text { кость }\end{array}$ & $\begin{array}{c}\text { Однородная, с } \\
\text { нарушенным или } \\
\text { ненарушенным } \\
\text { сгустком без газо- } \\
\text { образования жид- } \\
\text { кость }\end{array}$ & $\begin{array}{c}\text { Однородная, с } \\
\text { нарушенным или } \\
\text { ненарушенным } \\
\text { сгустком без газо- } \\
\text { образования жид- } \\
\text { кость }\end{array}$ & $\begin{array}{c}\text { Однородная, с } \\
\text { нарушенным или } \\
\text { ненарушенным } \\
\text { сгустком без газо- } \\
\text { образования жид- } \\
\text { кость }\end{array}$ \\
\hline $\begin{array}{l}\text { Вкус и за- } \\
\text { пах }\end{array}$ & $\begin{array}{l}\text { Чистые, кисломо- } \\
\text { лочные, с выра- } \\
\text { женным привку- } \\
\text { сом пастеризации }\end{array}$ & $\begin{array}{c}\text { Чистые, кисломо- } \\
\text { лочные, с выра- } \\
\text { женным привку- } \\
\text { сом пастеризации }\end{array}$ & $\begin{array}{l}\text { Чистые, кисломо- } \\
\text { лочные, с выра- } \\
\text { женным привку- } \\
\text { сом пастеризации }\end{array}$ & $\begin{array}{c}\text { Чистые, кисломо- } \\
\text { лочные, с выра- } \\
\text { женным привку- } \\
\text { сом пастеризации }\end{array}$ \\
\hline Цвет & $\begin{array}{c}\text { Светло-кремовый, } \\
\text { равномерный по } \\
\text { всей массе }\end{array}$ & $\begin{array}{c}\text { Светло-кремовый, } \\
\text { равномерный по } \\
\text { всей массе }\end{array}$ & $\begin{array}{c}\text { Светло-кремовый, } \\
\text { равномерный по } \\
\text { всей массе }\end{array}$ & $\begin{array}{c}\text { Светло-кремовый, } \\
\text { равномерный по } \\
\text { всей массе }\end{array}$ \\
\hline
\end{tabular}

Таблица 4 - Результаты физико-химической идентификации экспериментальных образцов ряженки

\begin{tabular}{|c|c|c|c|c|c|}
\hline \multirow{2}{*}{$\begin{array}{c}\text { Наименование } \\
\text { показателя }\end{array}$} & $\begin{array}{c}\text { ГОСТ } \\
31455-2012\end{array}$ & \multicolumn{3}{|c|}{ Значения исследования экспериментальных образцов } \\
\cline { 3 - 6 } & & $\begin{array}{c}\text { Фермерский } \\
\text { образец }\end{array}$ & $\begin{array}{c}\text { «Кремлевское } \\
\text { качество» }\end{array}$ & $\begin{array}{c}\text { «Молочное } \\
\text { царство» }\end{array}$ & $\begin{array}{c}\text { «Русское } \\
\text { молоко» }\end{array}$ \\
\hline $\begin{array}{c}\text { Массовая доля } \\
\text { жира, \%, не менее }\end{array}$ & $0-8,9$ & $0,0 / 6,0-8,0$ & $4,0 / 4,0$ & $4,0 / 2,8$ & $3,2 / 3,2$ \\
\hline Кислотность, ${ }^{\circ} \mathrm{T}$ & $\begin{array}{c}\text { От } 70 \text { до } \\
110 \text { включ. }\end{array}$ & 63 & 80 & 78 & 90 \\
\hline
\end{tabular}

Исследование видового состава заквасочных культур исследуемых образцов ряженки показала типичный состав (термофильные молочнокислые стрептококки), при этом морфологические свойства палочек в составе микрофлоры ряженки фермерского производства отличались от промышленных образцов, что свидетельствует о различии видового состава заквасочных культур, используемых в производстве ряженки фермерским и промышленным способом.

Экспертиза качества ряженки фермерского и промышленного производства, реализуемых в розничной сети юго-востока Московской области, показала, 
что при высоких потребительских предпочтениях фермерской ряженки ее состав и свойства не стабильны, ряд показателей не отвечает нормативным значениям. У промышленного образца ряженки «Молочное царство» выявлена информационная и качественная фальсификация.

\section{Список литературы}

1. ГОСТ 31455-2012. Ряженка. Технические условия. - М.: Стандартинформ, 2018. $-8 \mathrm{c}$.

2. Савина О.В., Зверев Д.С. Спреды - жировые продукты функционального назначения // Вестник РГАТУ имени П.А. Костычева - Рязань, 2017 - 136 с.

3. Тихомирова Н. А. Технология и организация производства молока и молочных продуктов [Текст]: учебник // Н. А. Тихомирова. - М.: ДеЛи принт, 2007. $-560 \mathrm{c}$. 